\title{
Endostatin and Vascular Endothelial Cell Growth Factor (VEGF) in Piglet Lungs: Effect of Inhaled Nitric Oxide and Hyperoxia
}

\author{
IKECHUKWU I. EKEKEZIE, DONALD W. THIBEAULT, MOHAMMAD H. REZAIEKHALIGH, \\ MICHAEL NORBERG, SHERRY MABRY, XIAOMING ZHANG, AND WILLIAM E. TRUOG \\ Department of Pediatrics, Section of Neonatology, Children's Mercy Hospitals and Clinics, University of \\ Missouri, Kansas City School of Medicine, Kansas City, Missouri 64108-9883, U.S.A.
}

\begin{abstract}
Pulmonary hyperoxic injury manifests as widespread alveolar-epithelial and microvascular endothelial cell necrosis, resolution of which requires angiogenesis. We investigated the hypothesis that inhaled nitric oxide (iNO) and hyperoxia each decreases lung vascular endothelial growth factor (VEGF) expression but increases endostatin and that concurrent administration of both gases will show a greater effect. Piglets were randomized to breathe for $5 \mathrm{~d}$ room air (RA); RA + NO (RA + 50 ppm NO), $\mathrm{O}_{2}$ (hyperoxia, $\mathrm{F}_{\mathrm{I}} \mathrm{O}_{2}>0.96$ ), $\mathrm{O}_{2}+\mathrm{NO}$, or $\mathrm{O}_{2}+$ $\mathrm{NO}+\mathrm{REC}\left(\mathrm{O}_{2}+\mathrm{NO}\right.$ plus recovery in $50 \% \mathrm{O}_{2}$ for $72 \mathrm{~h}$. After the piglets were killed, we measured lung capillary leak, VEGF mRNA, VEGF, and endostatin protein in homogenates, plasma, and lavage. VEGF mRNA decreased significantly with $\mathrm{O}_{2}$ and $\mathrm{O}_{2}+\mathrm{NO}$ compared with breathing RA $(p \leq 0.05)$. VEGF protein declined in the experimental groups with a significant reduction in the recovery group compared with the RA group ( $p$ $\leq 0.05$ ). Similar but more dramatic, endostatin declined in all groups relative to the RA group $(p<0.001)$. Lavage fluid VEGF
\end{abstract}

ABSTRACT

protein and lung capillary leak rose significantly with $\mathrm{O}_{2}$ and $\mathrm{O}_{2}$ + NO compared with RA, but endostatin was unchanged. At $72 \mathrm{~h}$ of recovery from hyperoxia, VEGF mRNA and lavage fluid VEGF but not lung VEGF protein had normalized. Hyperoxia and iNO suppresses lung endostatin expression, but iNO unlike hyperoxia alone does not alter lung VEGF production. Hyperoxia paradoxically raises lavageable VEGF levels. This latter effect and that on VEGF mRNA level but not protein is abrogated by recovery in reduced $\mathrm{F}_{\mathrm{I}} \mathrm{O}_{2}$ for 72 h. (Pediatr Res 53: 440-446, 2003)
Abbreviations
VEGF, vascular endothelial growth factor
iNO, inhaled nitric oxide
$\mathbf{F}_{\mathbf{I}} \mathbf{O}_{\mathbf{2}}$, fraction of inspired oxygen
TGF- $\boldsymbol{\beta} 1$, transforming growth factor- $\beta 1$
NO, nitric oxide
RA, room air

There are many pathologic manifestations of hyperoxic lung injury, but widespread endothelial cell damage and necrosis, with resultant high pulmonary microvascular permeability, are of particular importance $(1,2)$. The normal resolution of this vascular damage requires angiogenesis (3).

Several factors, including basic fibroblast growth factor, transforming growth factor- $\beta 1$ (TGF- $\beta 1$ ), IL-8, and vascular endothelial growth factor (VEGF), have been identified as important regulators or contributors to angiogenesis (4-7). However, VEGF is unique among these factors because it seems to be specific to endothelial cells in action, although

Received January 24, 2002; accepted October 4, 2002.

Correspondence: Ikechukwu I. Ekekezie, M.D., Section of Neonatology, Children's Mercy Hospitals and Clinics, 2401 Gillham Road, Kansas City, MO 64108, U.S.A.; e-mail: iekekezie@cmh.edu

Supported in part by NIH R-01 HL62079 and by a Physician Scientist Award from Children's Mercy Hospital (W.E.T.), Children's Mercy Hospital Clinical Scholar Award and K23 HL04264-03 (I.I.E.), and Katherine B. Richardson Foundation (D.W.T.).

DOI: 10.1203/01.PDR.0000050121.70693.1A proliferative effects on other cell types have now been reported $(8,9)$.

VEGF is a $35-$ to $46-\mathrm{kD}$ peptide produced by alveolarepithelial and other cell types in the lungs (10), with a pivotal role in angiogenesis. Mouse embryos heterozygous for VEGF gene do not survive, because of disruption of vascular development (11). VEGF has mitogenic and permeability effects on vascular endothelial cells $(6,12)$. It also can induce the expression of matrix degrading collagenases, thus permitting cell migration and vascular remodeling (13).

There are indications that the undue propensity of the pulmonary microvascular endothelial cells to undergo necrotic cell death in the presence of prolonged hyperoxic exposure may be a consequence of alterations in lung VEGF expression (14). The mechanisms that control lung VEGF expression are not fully understood, but there is evidence from an ex vivo model of hypoxia that endogenous nitric oxide (NO) downregulates VEGF production (15). 
Inhaled NO (iNO) is used in conjunction with high fraction of inspired oxygen $\left(\mathrm{F}_{\mathrm{I}} \mathrm{O} 2\right)$ to treat neonatal pulmonary disorders $(16,17)$. The possibility that iNO, with or without hyperoxia, may alter lung VEGF dynamics with potential beneficial or adverse consequences for microvascular endothelial cell viability has not been examined.

Although VEGF is a potent angiogenic factor, its net effect would depend on the balance with antiangiogenic factors. Endostatin, a proteolytic derivative of the carboxy terminal domain of basement membrane type XVIII collagen, has potent antiangiogenic properties (18). Endostatin has a specific inhibitory effect on endothelial cell proliferation (19). Like VEGF, it is bound to the matrix; therefore, widespread activation of lung proteases, as occurs with hyperoxia (20), may increase lung endostatin level. Also, because NO and VEGF are reported to increase collagenase expression $(12,21)$, they could potentially increase endostatin level, inhibiting endothelial cell repair. The effects of $\mathrm{NO}$ and hyperoxia on lung endostatin level or on its relative balance with VEGF after exposure to either or both gases is unknown.

The present study investigated the hypotheses that iNO and hyperoxia each decreases lung VEGF expression but increases endostatin level and that concurrent administration of both gases will have an additive or greater effect on lung VEGF and endostatin levels than either gas alone. We used a young piglet model with rapidly growing lungs to examine the individual and combined effects of exposure to iNO and hyperoxia on lung VEGF in relation to lung endostatin and capillary leak.

\section{METHODS}

Animal exposure and killing. We previously reported on our animal exposure methods in detail (22). Briefly, we randomized 10- to 17-day-old male piglets into groups to breathe in a chamber for $5 \mathrm{~d} 1)$ room air $(\mathrm{RA})(n=6) 2) \mathrm{RA}+50 \mathrm{ppm}$ $\mathrm{NO}$ (iNO; $n=6$ ), 3) $\mathrm{O}_{2}$ (hyperoxia, $\mathrm{F}_{\mathrm{I}} \mathrm{O}_{2} \geq 0.96 ; n=6$ ), or 4) $\mathrm{O}_{2}+\mathrm{NO}$ (hyperoxia with iNO; $n=6$ ). In an additional experiment, piglets group 5) $\mathrm{O}_{2}+\mathrm{NO}+\mathrm{REC}$ (recovery group; $n=6$ ), piglets were allowed to recover in $50 \% \mathrm{~F}_{\mathrm{I}} \mathrm{O}_{2}$ for $72 \mathrm{~h}$ after initial exposure to hyperoxia. Fifty percent $\mathrm{O}_{2}$ was chosen instead of room air to prevent the recovering animals from dying. The animals had free access to food and water. Medical grade $\mathrm{O}_{2}$ and NO (Puritan Bennett, Overland Park, KS, U.S.A.) were routed by way of connectors and regulators to the inlet port of the exposure chamber. Humidified $\mathrm{O}_{2}$ and $\mathrm{NO}$ were introduced at flow rates sufficient to maintain chamber concentrations at $\geq 96 \%$ and $50 \mathrm{ppm}$, respectively, throughout the experiment. Four 150-g soda lime containers and 500-g activated charcoal containers (Sigma Chemical Co., St. Louis, MO, U.S.A.) were used to scavenge carbon dioxide $\left(\mathrm{CO}_{2}\right)$ and nitrogen dioxide $\left(\mathrm{NO}_{2}\right)$. Chamber outlet port gas concentration was monitored for $\mathrm{O}_{2}$ (Hudson Medical, Temecula, CA, U.S.A.), $\mathrm{CO}_{2}$ (Model ABL30 Blood Gas Analyzer; Radiometer, Westlake, OH, U.S.A.), and $\mathrm{NO}$ and $\mathrm{NO}_{2}$ (Sensor Stik, NO Model 4584 and $\mathrm{NO}_{2}$ Model 4586; Exidyne Instruments, Exton, PA, U.S.A.).

At the end of the exposure period, the piglets were anesthetized with $2 \mathrm{mg} / \mathrm{kg}$ xylazine, $20 \mathrm{mg} / \mathrm{kg}$ ketamine, and $40 \mathrm{mg} / \mathrm{kg}$ sodium pentobarbital before instrumentation. Killing was accomplished with high-dose pentobarbital, and the lungs were harvested promptly. The right lung was lavaged with six aliquots of $25 \mathrm{~mL}$ of PBS, and the recovered lavage fluid was filtered to separate cells then stored at $-80^{\circ} \mathrm{C}$ until analyzed. Pieces of the left lower lobe were minced, then frozen in liquid nitrogen and stored at $-80^{\circ} \mathrm{C}$ for hybridization studies. The remaining left upper lobe was fixed in $4 \%$ formalin and used for immunohistochemistry. The Institutional Animal Care Utilization Committee of the University of Missouri at Kansas City approved the study.

$R N A$ extraction, probe preparation, and ribonuclease protection assay for VEGF mRNA. Total RNA was isolated from lung tissue samples using Tri-Reagent (Sigma Chemical Co.) according to the manufacturer's instructions. Multiprobe ribonuclease protection assay for VEGF mRNA was performed according to the manufacturer's protocol (Pharmingen, San Diego, CA, U.S.A.). Briefly, $\left[{ }^{32} \mathrm{P}\right]$ UTP-labeled antisense RNA probes were generated for VEGF, the housekeeping genes L32 and GAPDH by in vitroT7 polymerase directed transcription from a mix of their porcine partial cDNA templates. The synthesized probe set was diluted to a final concentration of 2 $\times 10^{5} \mathrm{cpm} / \mu \mathrm{L}$. Two microliters of the diluted probe set was mixed and hybridized to $6 \mu \mathrm{g}$ of total lung RNA isolate in $8 \mu \mathrm{L}$ of hybridization buffer. The samples were then incubated for $16 \mathrm{~h}$ in water bath prewarmed to $90^{\circ} \mathrm{C}$ but immediately decreased to $56^{\circ} \mathrm{C}$, allowing the temperature to ramp down slowly during this period. Unhybridized RNA, including probes, were then digested with RNase $\mathrm{A}$ and $\mathrm{T} 1$ for $60 \mathrm{~min}$ at $37^{\circ} \mathrm{C}$. This was followed by phenol-chloroform-isoamylalcohol extraction of the hybridized or protected RNA duplexes after treatment with proteinase $\mathrm{K}$. The hybridized RNA were then resolved on a $5 \%$ acrylamide, $7 \mathrm{M}$ urea gel by electrophoresis, allowing for separation of protected or duplex RNA strands into discrete bands based on the graded lengths of the probe cDNA templates. Gels were dried under vacuum for $\sim 1$ $\mathrm{h}$ at $80^{\circ} \mathrm{C}$. Dry gels were then developed overnight at $-70^{\circ} \mathrm{C}$ on a film (Kodak X-AR; Eastman Kodak, Rochester, NY, U.S.A.) in a cassette equipped with an intensifying screen. For quantitation of mRNA, the band intensities of the autoradiograms were measured on densitometer (Personal SI) running the Image Quant software (Molecular Dynamics, Sunnyvale, CA, U.S.A.). The values obtained for VEGF were then normalized to that of the housekeeping gene L32.

VEGF protein in lung homogenate, plasma, and lavage. VEGF protein level in lung homogenate, plasma, and lung lavage fluid was determined by competitive ELISA, using a commercially available kit according to the manufacturer's instructions (Chemicon International, Temecula, CA, U.S.A.). Briefly, for lavage fluid, $100 \mu \mathrm{L}$ of standards and samples were added to wells in a microtiter plate followed by $25 \mu \mathrm{L}$ of VEGF antibody, then allowed to incubate for $3 \mathrm{~h}$. Next, to the mixtures was added $25 \mu \mathrm{L}$ of VEGF antibody biotin conjugate followed by incubation at room temperature for $30 \mathrm{~min}$, then wells were aspirated and washed four times with wash buffer. Fifty microliters of streptavidin alkaline phosphatase conjugate was then added to each well followed by incubation for $30 \mathrm{~min}$ at room temperature. After aspiration and washing four times 
with wash buffer, $200 \mu \mathrm{L}$ of stabilized chromogen was added to each well followed by incubation for $30 \mathrm{~min}$. The absorbance was read from a microtiter plate optical reader at 492 $\mathrm{nm}$. The VEGF concentration in the samples was interpolated from the standard curve.

Plasma and lung homogenate VEGF protein were assayed with the same kit as described above except for modifications in the protocol requiring use of different diluents and sample volumes as instructed by the manufacturers. The gram of total protein per lung normalized VEGF proteins in the lung homogenates.

Endostatin in lung homogenate, plasma, and lavage. Endostatin level in lung homogenate, plasma, and lavage fluid was measured using a commercially available competitive ELISA kit according to the manufacturer's instruction (Chemicon International). The method was essentially similar to that described for VEGF above. The values obtained for endostatin in the homogenates were normalized to that of total protein per gram of lung.

Lung vascular permeability. As we previously reported, lung vascular permeability was determined by SDS-PAGE resolution of lavage fluid protein molecular weight profile (22). Data obtained from densitometric analysis of the albumin $(60$ $\mathrm{kD})$ band in the experimental groups were normalized to that of the RA group.

Lung histology, apoptosis, and VEGF immunohistochemistry. Paraffin-embedded, formalin-fixed lung sections were cut $4 \mu \mathrm{m}$ thick and mounted on positively charged glass slides. After deparaffinization and rehydration, endogenous peroxidase was quenched with hydrogen peroxide. A hematoxylin and eosin preparation of the lung sections was prepared for histology. Apoptosis was detected by TUNEL assay using a commercially available kit, Apo-tag Plus (ONCOR, Gaithersburg, MD, U.S.A.) according to manufacturer's directions.

VEGF distribution and abundance in the lungs were also assessed by immunohistochemical staining. Sections were immunostained with rabbit polyclonal VEGF antibody (Santa Cruz Biotechnology, Santa Cruz, CA, U.S.A.) using a modified avidin-biotin-peroxidase method (23). Briefly, nonspecific binding was blocked by incubating sections in blocking serum (DAKO, Carpinteria, CA, U.S.A.) for $10 \mathrm{~min}$, followed by primary antiserum overnight. After washing, sections were incubated with biotinylated IgG and stained with immunoperoxidase technique according the manufacturer's instructions (Vectorstain ABC Elite Kit; Vector Laboratories, Burlingame, CA, U.S.A.). Antigenic sites were visualized by addition of the chromogen 3'3' diaminobenzidine. Slides were counterstained with hematoxylin. Negative control slides were prepared using the same technique but omitting the primary antibody or adding a nonimmune serum. The sections were visualized under light microscopy, and VEGF immunostaining was semiquantified from scores assigned by two blinded observers using a $0-3$ scale: 0 , no staining; 1, light staining; 2, moderate staining; 3 , heavy staining.

Statistics. Statistical analysis was performed using a computerized statistical software package, INSTAT (GraphPad Software, Inc., San Diego, CA, U.S.A.). Parametric data were analyzed with one-way ANOVA, and nonparametric data were analyzed with Kruskal Wallis test. Posttest with Tukey Kramer and Standard Neuman Keuls were performed as appropriate. $P<0.05$ was considered significant. Results are expressed as mean \pm SD unless noted otherwise.

\section{RESULTS}

All animals survived the exposure experiment, but the $\mathrm{O}_{2}$ and $\mathrm{O}_{2}+\mathrm{NO}$ group, unlike the RA and $\mathrm{RA}+\mathrm{NO}$ group, manifested signs of respiratory distress ranging from tachypnea to severe retraction by the end of the exposure period.

Lung VEGF mRNA. Figure 1 shows representative lanes of the bands obtained from ribonuclease protection assay for VEGF mRNA transcripts in the lungs of piglet groups. The mRNA expression level of the housekeeping gene L32 was stable in all of the experimental groups and therefore was used to normalize the data for VEGF. Mean values for total lung VEGF mRNA in the $\mathrm{O}_{2}$ and $\mathrm{O}_{2}+\mathrm{NO}$ groups were significantly less than that of the RA group ( $p<0.001$; Fig. 2). In contrast, lung VEGF mRNA values from the RA + NO and the recovery group were not different from that of the RA group. Thus, $\mathrm{O}_{2}$ and $\mathrm{O}_{2}+\mathrm{NO}$ exposure but not iNO alone decreases lung VEGF mRNA expression. Recovery at reduced $\mathrm{F}_{\mathrm{I}} \mathrm{O}_{2}$ for $72 \mathrm{~h}$ after previous exposure to $\mathrm{O}_{2}+\mathrm{NO}$ restores VEGF mRNA to control levels.

VEGF protein in lung homogenate. To assess whether the changes observed in VEGF mRNA after exposure to the study gases are reflected in lung VEGF protein abundance, we measured VEGF protein in whole-lung homogenates. The results are shown in Fig. 3. Lung VEGF protein values for the

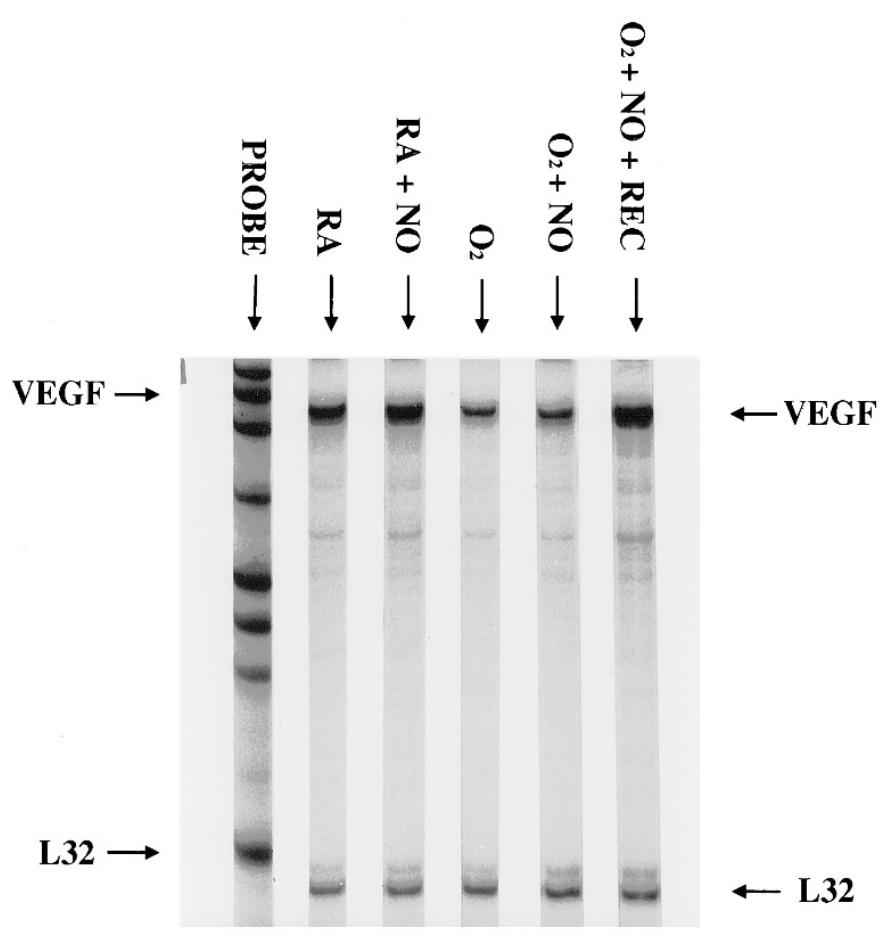

Figure 1. Autoradiogram showing representative lanes for mRNA bands obtained from the piglet experimental groups from ribonuclease protection assay for whole-lung VEGF and L32. Note that the mRNA transcript of the housekeeping gene L32 seemed relatively unchanged among the groups. 


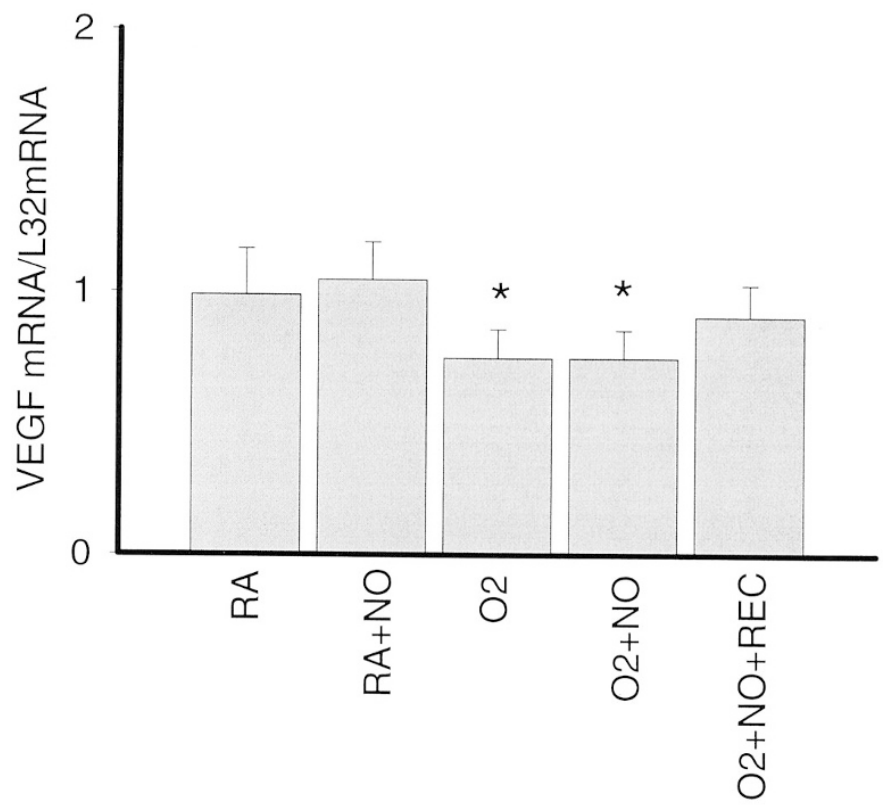

Figure 2. Densitometric values obtained for VEGF mRNA bands in the autoradiogram from the piglet experimental groups. The data were normalized to that of the housekeeping gene L32, mRNA. Note the decreased values of VEGF mRNA in the $\mathrm{O}_{2}$ and $\mathrm{O}_{2}+\mathrm{NO}$ groups compared with the RA group. The recovery group was not different from the RA group $\left({ }^{*} p<0.05\right.$ compared with RA group mean $\pm \mathrm{SD}$ ).

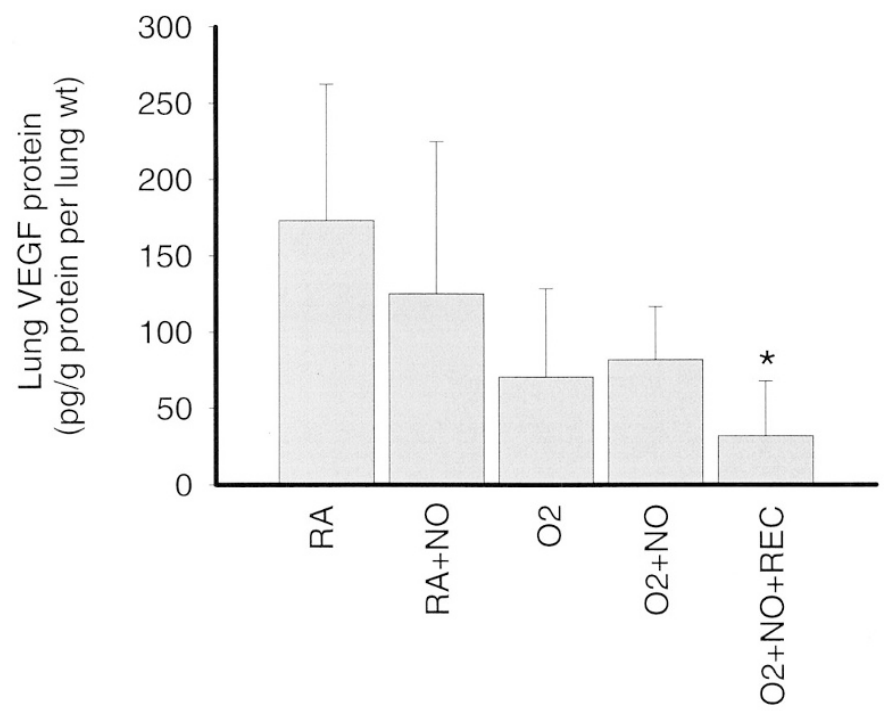

Figure 3. VEGF protein in lung homogenates from the piglet experimental groups. Note the significant decline in the mean value for the recovery group relative to the RA group's value $\left({ }^{*} p<0.05\right.$ compared with RA group $\left.\pm \mathrm{SD}\right)$.

$\mathrm{O}_{2}$ and $\mathrm{O}_{2}+\mathrm{NO}$ piglet group lungs were lower than the RA group's mean value, but the difference did not attain statistical significance. However, the recovery piglet group showed a statistically reduced level of lung VEGF protein compared with the RA group $(p<0.01)$.

Lung histology, apoptosis, and VEGF immunohistochemistry. The staining abundance, cellular, and tissue distribution of VEGF in the piglet lungs were studied under light microscopy. Mean scores for lung VEGF protein abundance obtained for the experimental groups from semiquantitative scoring under light microscopy of immunohistochemically prepared slides of lung sections are shown (Fig. 4). In corroboration with the data obtained for VEGF protein in lung homogenates (Fig. 3 ), the score for the recovery piglet group is significantly lower than that for the RA group $(p<0.05)$. The other experimental groups, although with quantitatively lower mean scores than the RA group, were not significantly different.

VEGF immunostain distribution shows that it is highly abundant in airway and alveolar septal cells (Fig. 5a). Other specific staining cell types include lung macrophages and alveolar-epithelial and endothelial cells. Vascular smooth muscle cells and fibroblasts do not seem to stain. VEGF staining distribution pattern was not altered by the experimental interventions, but, as noted in Fig. 4, VEGF immunostain abundance did decline significantly in the recovery piglet group lungs (Fig. 5b).

Lung histology exam and TUNEL assay for apoptosis showed presence of cellular and interstitial edema with increased numbers of inflammatory cells and apoptotic nuclei in the $\mathrm{O}_{2}-$ and $\mathrm{O}_{2}+\mathrm{NO}-$ exposed piglet lungs. The apoptotic cells seemed to be endothelial and epithelial cells (not shown).

VEGF protein in lung lavage fluid and plasma. Mean lavage fluid VEGF protein levels in the $\mathrm{O}_{2}$ and $\mathrm{O}_{2}+\mathrm{NO}$ groups were significantly greater than that of the RA group ( $p$ $<0.001$; Fig. 6). However, there was no significant difference between the mean values for the $\mathrm{O}_{2}$ and $\mathrm{O}_{2}+\mathrm{NO}$ groups. The $\mathrm{RA}+\mathrm{NO}$ and the recovery groups had lavage fluid VEGF protein mean values that were not different from that of the RA group. Thus, recovery in reduced $\mathrm{F}_{\mathrm{I}} \mathrm{O}_{2}$ for $72 \mathrm{~h}$ after combined iNO-hyperoxia exposure restored lavage fluid VEGF back to control levels.

To determine whether the hyperoxia-induced increase in lavage fluid VEGF concentration stems from transudation of

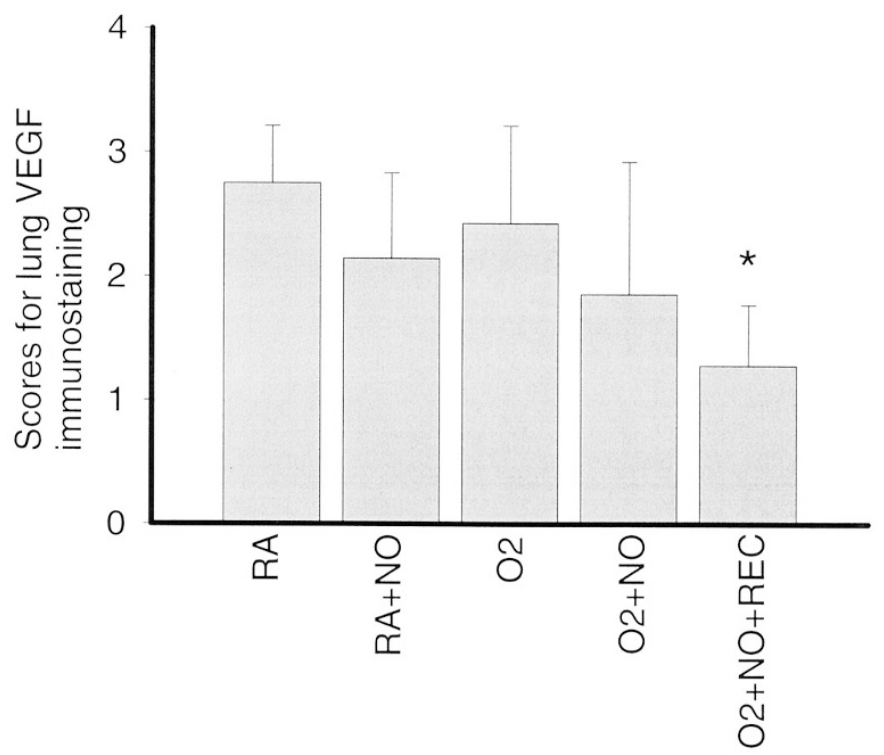

Figure 4. Lung VEGF abundance in the piglet experimental groups as determined from immunostaining scores. Note the similarity to the findings for VEGF protein in lung homogenates as shown in Fig. 3. The recovery group had a significantly lower mean score than the RA group $\left({ }^{*} p<0.05\right.$ compared with the RA group). 


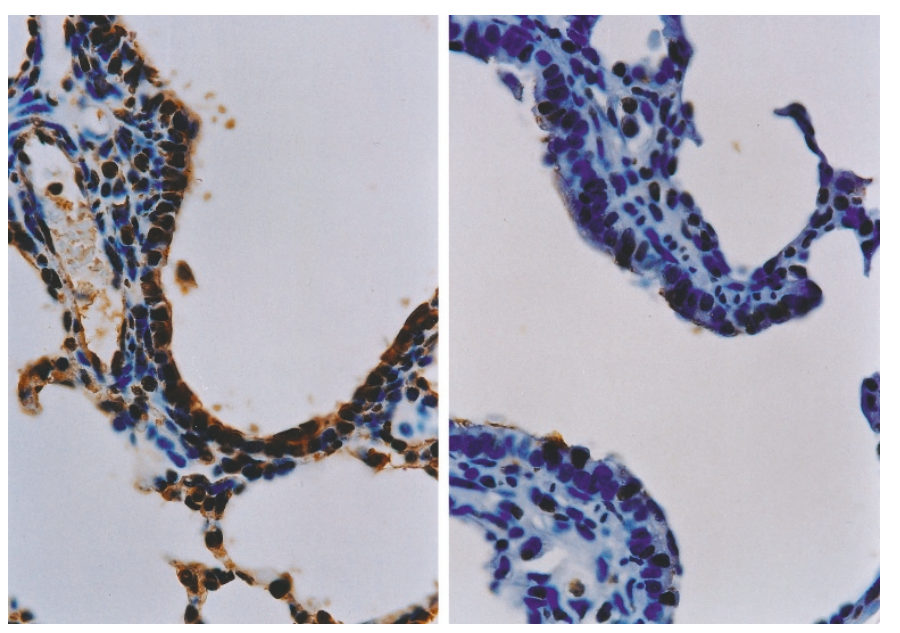

Figure 5. (a) VEGF distribution in an RA piglet lung. Note staining of endothelial, airway, and alveolar-epithelial cells. Vascular smooth muscle cells and fibroblast do not stain. VEGF distribution pattern was similar in all groups. (b) VEGF distribution in a recovery group piglet lung. Note the decrease in VEGF immunostaining.

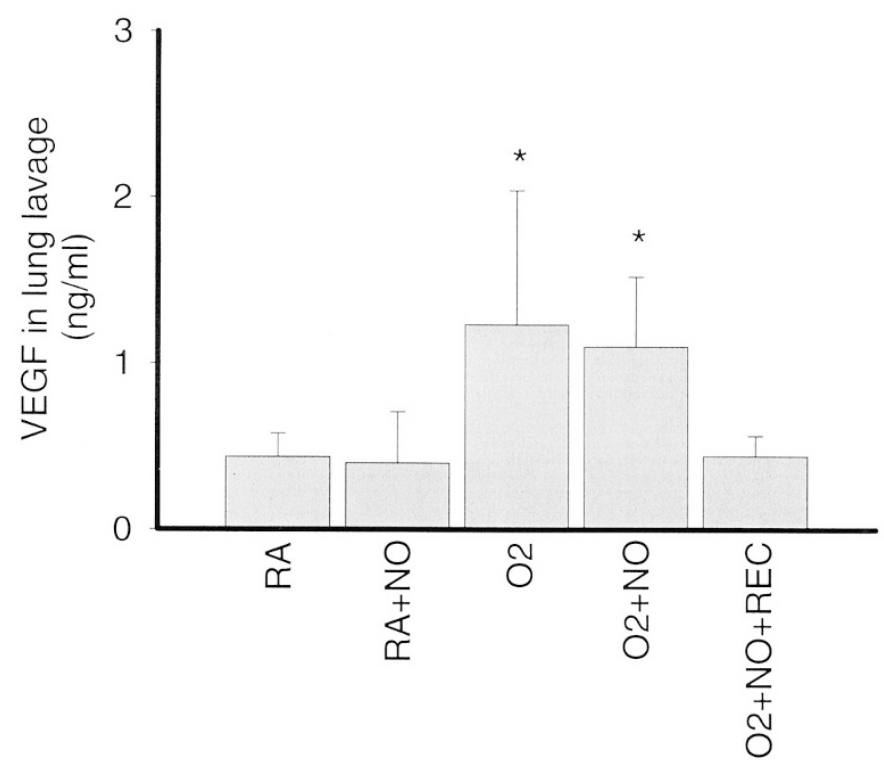

Figure 6. Mean values obtained for VEGF protein in the lung lavage fluid from the piglet experimental groups. The results are expressed in $\mathrm{pg} / \mathrm{mL}$. Note the increased level of VEGF in the lavage fluids of the $\mathrm{O}_{2}$ and $\mathrm{O}_{2}+\mathrm{NO}$ piglet groups relative to the RA group mean value. The recovery group's mean value was not different from that of the RA control group $\left({ }^{*} p<0.05\right.$ compared with $\mathrm{RA}$ group $\pm \mathrm{SD})$.

plasma VEGF into the alveolar space as a result of hyperoxia increasing vascular permeability, we measured plasma VEGF in the groups. VEGF was barely detectable in plasma from all groups (data not shown).

Mean lavage fluid albumin concentration was measured as an index of lung capillary permeability. The lavage fluid from the $\mathrm{O}_{2}$ and $\mathrm{O}_{2}+\mathrm{NO}$ piglet groups had significantly elevated albumin levels compared with that of the RA group $(p<0.05$; Fig. 7). The RA + NO group's level did not differ from that of the RA group.

Lung endostatin. Mean values for endostatin in total lung homogenates for the $\mathrm{RA}+\mathrm{NO}, \mathrm{O}_{2}$, and $\mathrm{O}_{2}+\mathrm{NO}$ experimen-

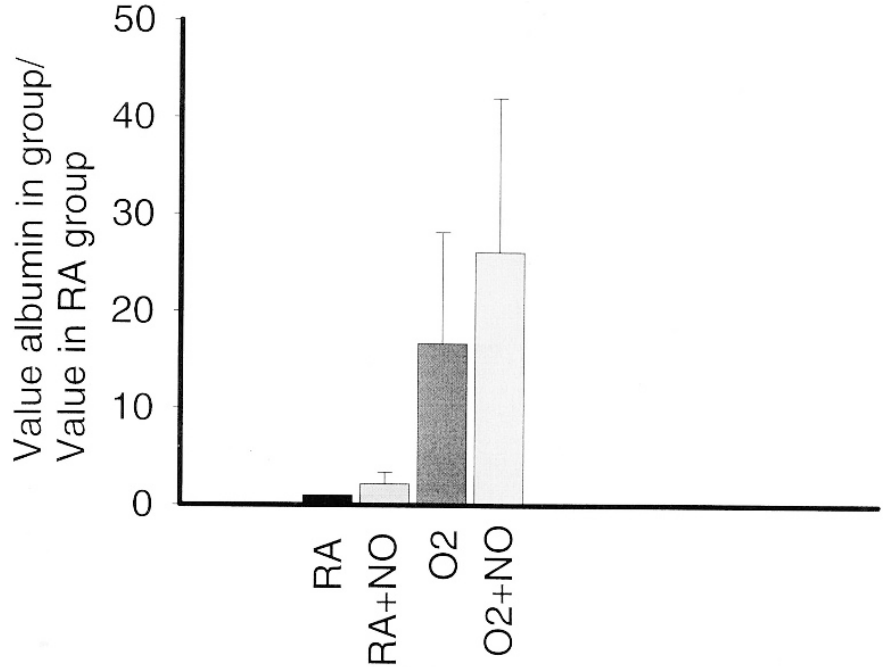

Figure 7. Mean lavage fluid albumin levels in the experimental groups, an indirect measure of lung capillary leak. Note that the $\mathrm{O}_{2}$ and $\mathrm{O}_{2}+\mathrm{NO}$ group mean values are greater than that of the RA group $\left({ }^{*} p<0.05\right.$ compared with the RA group).

tal groups showed a significant reduction compared with that of the RA group ( $p<0.001$; Fig. 8). The decline in lung endostatin persisted and was most pronounced in the recovery piglet group compared with the RA group $(p<0.0001)$. Thus, iNO and hyperoxia decrease lung endostatin with the effect lasting up to $72 \mathrm{~h}$ after exposure. No significant differences in plasma and lavage fluid endostatin levels were detected between the experimental groups and the RA control group.

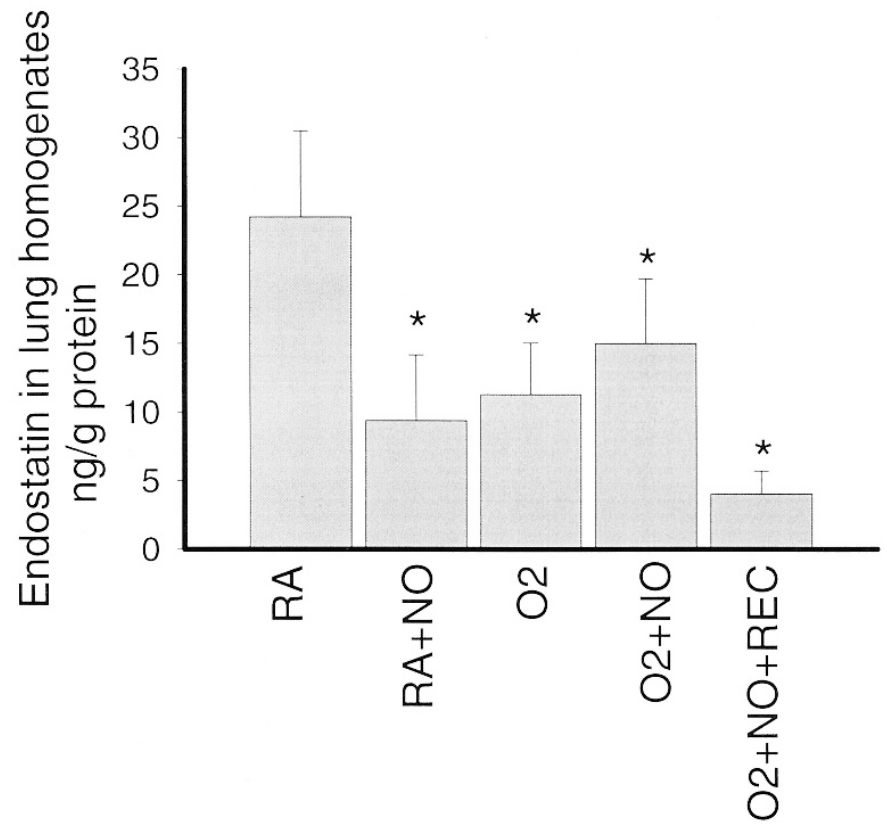

Figure 8. Mean values obtained for endostatin in lung homogenates from the experimental groups. Note the decreased mean endostatin values in the lungs of the experimental piglets relative to that of the RA control group. Also the recovery groups mean value is significantly less than that of any other group $\left({ }^{*} p<0.05\right.$ compared with the RA group). 


\section{DISCUSSION}

Hyperoxic lung injury is characterized by widespread alveolar-epithelial and microvascular endothelial cell damage and necrosis, the normal resolution of which is dependent on angiogenesis (1-3). VEGF and endostatin are important regulators of angiogenesis $(11,18,19)$. We report from this study that concurrent exposure to hyperoxia and iNO or hyperoxic exposure by itself for $5 \mathrm{~d}$ decreases lung VEGF expression in young piglets. However, allowing the piglets to recover for $72 \mathrm{~h}$ at a reduced $\mathrm{F}_{\mathrm{I}} \mathrm{O}_{2}$ level abrogates the depressant effect on lung VEGF mRNA expression but not that on VEGF protein, which remains depressed at this time point. Also, we report that the decrease in lung VEGF expression with concurrent iNO and hyperoxia or with hyperoxia exposure alone is accompanied by a paradoxical rise in lavageable lung VEGF protein fraction. We found no evidence of increased transudation of plasma VEGF protein into the alveolar space; therefore, the rise in lavage fluid VEGF is probably due to proteolytic release and cleavage of extracellular matrix-bound VEGF protein.

In contrast to the findings for lung VEGF, we found that lung endostatin not only decreased with iNO and hyperoxia exposure but that the effect persists beyond $3 \mathrm{~d}$ after exposure. To our knowledge, this is the first report to describe the effect of iNO with or without hyperoxia on lung VEGF and lung endostatin.

Previous investigators have reported on the effects of hyperoxia on lung VEGF expression. Klekamp et al. (14) Maniscalco et al. (24), and Watkins et al. (25) all have reported that hyperoxia reduces lung VEGF expression. Data obtained from the present study regarding the effect of hyperoxia are largely consistent with these reports. In their experiments, Maniscalco et al. and Watkins et al. reported that lung VEGF production returned to normal in New Zealand rabbits exposed to hyperoxia, after they were allowed to recover for $3 \mathrm{~d}$ at a reduced $\mathrm{F}_{\mathrm{I}} \mathrm{O}_{2}$ level of 0.6 . The current study found that with combined iNO-hyperoxia exposure, although lung VEGF mRNA expression is restored to normal by recovery at $0.5 \mathrm{~F}_{\mathrm{I}} \mathrm{O}_{2}$ for $72 \mathrm{~h}$, lung VEGF protein remains diminished. This may indicate persistence of a blockade in VEGF translation and hence production. It is possible, although less likely, that the time points chosen for this experiment did not fully accommodate the time lag necessary for changes in VEGF mRNA level to reflect on VEGF protein abundance. As a transcriptionally regulated factor, changes in VEGF mRNA expression level should precede changes in VEGF protein abundance.

We found that the rise in lavage fluid VEGF protein during hyperoxia with or without iNO declined to control level after the piglets were allowed to recover for $3 \mathrm{~d}$. This contrasts with the observation of Watkins et al., who reported several-fold elevations in lavage fluid VEGF protein in New Zealand rabbits recovering from hyperoxia (25). It is possible that differences in concentration and duration of hyperoxia exposure before recovery or in species response may account for the discrepancy. Nevertheless, it is interesting to note that both studies corroborate each other with respect to the finding of a paradoxical rise in lavage fluid VEGF protein and a decline in lung VEGF mRNA after exposure to hyperoxia.
The rise in lavage fluid VEGF protein is probably secondary to proteolytic release of extracellular matrix-bound VEGF and their subsequent cleavage to readily diffusable lower molecular weight isoforms. Indirect support for this possibility comes from data obtained in the present study showing higher VEGF protein concentrations in lavage fluids of all piglet groups relative to barely detectable plasma levels. Thus, increased transudation of plasma VEGF into the alveolar space cannot explain the rise in lavageable VEGF. Lung VEGF exists mostly in the form of higher molecular weight, less diffusable isoforms that are bound to the extracellular matrix. Its bioavailability is regulated by both genetic and proteolytic mechanisms (26). Hyperoxia is known to activate proteases, including urokinase type plasminogen activator and matrix metalloproteinases (27-29), that are capable of cleaving and releasing extracellular matrix-bound proteins. Thus, increased mobilization of matrix-bound VEGF protein and their cleavage to more diffusable isoforms would lead to a rise in lavageable VEGF. Interestingly, the highly diffusable lower molecular weight VEGF isoforms are the only isoforms with demonstrated potent mitogenic ability $(30,31)$ and probably do account for most VEGF actions.

We found increased lung permeability and apoptosis coincident to the changes in lung VEGF in the hyperoxia with or without iNO-exposed piglets. The increased permeability is consistent with alveolar capillary barrier disruption or damage. VEGF as a permeability and survival factor for endothelial cells likely contributed to these findings, although such contribution cannot be distinguished from the effects of hyperoxia acting through other known mechanisms.

Tuder et al. (11) in their experiments studying the effect of hypoxia on lung VEGF expression examined the separate effects of administration of exogenous NO donor, sodium nitroprusside, and endogenous NO production blocker LNAME and concluded that NO-dependent mechanisms modulate lung VEGF production. Unfortunately, several important differences in methodology preclude any direct comparison between the current study and that of Tuder et al. We used an in vivo hyperoxic piglet model instead of an ex vivo hypoxic rat lung model to study $\mathrm{NO}$ effects. Observations made in ex vivo models often differ from events in the intact animal. Perhaps even more important is that the present study examined the effect of iNO, whose actions are restricted essentially to the lungs, as opposed to the systemic acting NO donor sodium nitroprusside used in their study.

We had expected that NO and hyperoxia, through their ability to activate proteases in the lung, would lead to a rise in lung endostatin via increased release from basement membrane type XVIII collagen (18). However, the reverse was true with both iNO and hyperoxia causing a significant and lasting decline in lung endostatin up to $3 \mathrm{~d}$ after exposure. A likely explanation is that free endostatin is not immune to the actions of activated proteases and, therefore, is cleaved to other substances. As an angiogenesis inhibitory factor, endostatin could minimize or exacerbate the impact of changes in lung VEGF on angiogenesis and on lung repair after injury.

We had reasoned that changes in lung endostatin would be reflected in its lavage fluid level, because it is a proteolytic 
derivative from the $\mathrm{C}$-terminal domain of the $\alpha$-chain of basement membrane type XVIII collagen (18). However, to our surprise, plasma and lavage fluid endostatin levels were unchanged with exposure to either gas. To our knowledge, this is the only report on the effect of hyperoxia and NO on lung endostatin.

The findings from the present study are significant for several reasons. First, iNO, unlike hyperoxia, does not alter lung VEGF production. Also, concurrent iNO administration with hyperoxia does not exacerbate or ameliorate hyperoxic effects on lung VEGF dynamics. One implication of the finding is that the decline in endothelial cell viability stemming from diminished production of the endothelial cell survival factor VEGF in the presence of hyperoxia is not further aggravated by coadministration of iNO. This observation is reassuring from a clinical standpoint. Next, we showed that lung VEGF gene transcript abundance is soon restored to control levels after hyperoxia exposure even in the presence of $50 \% \mathrm{O}_{2}$ but not VEGF translation, which remains impaired for much longer. This suggests the existence after hyperoxia exposure of a prolonged period of potentially deleterious consequences to endothelial cell viability that may adversely affect lung repair. Finally, we report for the first time that iNO and hyperoxia suppress lung endostatin level. This suppressive effect of iNO and hyperoxia on lung endostatin may lessen some of hyperoxia's adverse effect on angiogenesis.

The limitations of this study include a single dose and a single exposure duration of iNO studied as well as absence of the potentially confounding effects of mechanical ventilation as occurs in the clinical setting. Nevertheless, the study provides useful new information on the effects of iNO on VEGF and endostatin.

\section{CONCLUSIONS}

In summary, this study found that $\mathrm{iNO}$, unlike hyperoxia alone or their concurrent exposure, does not alter lung VEGF production. Hyperoxia with or without iNO reduces lung VEGF production but increases lavage fluid VEGF protein. This latter effect and that on VEGF gene transcription but not its mRNA translation is abated by recovery at reduced $\mathrm{F}_{\mathrm{I}} \mathrm{O}_{2}$ level for $72 \mathrm{~h}$. Unlike its lack of effect on lung VEGF, iNO, like hyperoxia, induces a sustained decrement on lung endostatin, lasting longer than $72 \mathrm{~h}$ after exposure.

We speculate that strategies aimed at preservation or promotion of lung VEGF expression and its relative balance with endostatin may mitigate or attenuate hyperoxia-induced pulmonary microvascular injury. Further studies specifically aimed at investigating these prospects as well as undertaking a comprehensive examination of the effect of iNO and $\mathrm{O}_{2}$ on VEGF and endostatin are warranted.

Acknowledgments. We thank Mary S. Bailey for administrative assistance and patience in preparation of this manuscript.

\section{REFERENCES}

1. Crapo JD 1986 Morphologic changes in pulmonary oxygen toxicity. Ann Rev Physiol 48:721-731

2. Fracica PJ, Knapp MJ, Piantadosi CA, Takeda K, Fullkerson WJ, Coleman RE, Wolfe WG, Crapo JD 1991 Response of baboons to prolonged hyperoxia: physiology and qualitative pathology. J Appl Physiol 71:2352-2362

3. Jakkula M, Le Cras TD, Gebb S, Hirth KP, Tuder RM, Voelkel NF, Abman SH 2000 Inhibition of angiogenesis decreases alveolarization in the developing rat lung. Am J Physiol 279:L600-L607

4. Klagsbrun M, D’Amore PA 1991 Regulators of angiogenesis. Annu Rev Physiol 53:217-239

5. Folkman J, Shing Y 1992 Angiogenesis. J Biol Chem 267:10931-10934

6. Keck PJ, Hauser SD, Krivi G, Sanzo K, Warren T, Feder J, Connolly DT 1989 Vascular permeability factor, an endothelial cell mitogen related to PDGF. Science 246:1309-1312

7. Leung DW, Cachianes G, Kuang W-J, Goeddel DV, Ferrara N 1989 Vascular endothelial growth factor is a secreted angiogenic mitogen. Science 246:1307-1309

8. Thomas KA 1996 Vascular endothelial growth factor, a potent and selective angiogenic agent. Biol Chem 271:603-606

9. Brown KR, England KM, Goss KL, Snyder JM, Acarregui MJ 2001 VEGF induces airway epithelial cell proliferation in human fetal lung vitro. Am J Physiol 281:L1001-L1010

10. Monacci WT, Merrill MJ, Oldfield EH 1993 Expression of vascular permeability factor/vascular endothelial growth factor in normal rat tissues. Am J Physiol 264:C995-C1002

11. Ferrara N, Carver-Moore K, Chen H, Dowd M, Lu L, O'Shea S, Powell-Braxton L, Hillan KJ, Moore MJ 1996 Heterozygous embryonic lethality induced by targeted inactivation of the VEGF gene. Nature 380:439-442

12. Hippenstiel S, Krull M, Ikemann A, Risau W, Clauss M, Suttorp N 1998 VEGF induces hyperpermeability by a direct action on endothelial cells. Am J Physiol 274:L678-L684

13. Unemori EN, Ferrara N, Bauer EA, Amento EP 1992 Vascular endothelial growth factor induces interstitial collagenase expression in human endothelial cells. J Cell Physiol 153:557-562

14. Klekamp JG, Jarzecka K, Perkett EA 1999 Exposure to hyperoxia decreases the expression of vascular endothelial growth factor and its receptors in adult rat lungs. Am J Pathol 154:823-831

15. Tuder RM, Flook BE, Voelkel NF 1995 Increased gene expression for VEGF and the VEGF receptors KDR/Flk and Flt in lungs exposed to acute or to chronic hypoxia. Modulation of gene expression by nitric oxide. J Clin Invest 95:1798-1807

16. Kinsella JP, Abman SH 2000 Inhaled nitric oxide: current and future uses in neonates. Semin Perinatol 24:387-395

17. Banks BA, Seri I, Ischiropoulos H, Merrill J, Rychik J, Ballard RA 1999 Changes in oxygenation with inhaled nitric oxide in severe bronchopulmonary dysplasia. Pediatrics 103:610-618

18. Sasaki T, Fukai N, Mann K, Gohring W, Olsen BR, Timpl R 1998 Structure, function and tissue forms of the C-terminal globular domain of collagen XVIII containing the angiogenesis inhibitor endostatin. EMBO J 17:4249-4256

19. O'Reilly MS, Boehm T, Shing Y, Fukai N, Vasios G, Lane WS, Flynn E, Birkhead JR, Olsen BR, Folkman J 1997 Endostatin: an endogenous inhibitor of angiogenesis and tumor growth. Cell 88:277-285

20. Kerr JS, Chae CU, Nagase H, Berg RA, Riley DJ 1987 Degradation of collagen in lung tissue slices exposed to hyperoxia. Am Rev Respir Dis 135:1334-1339

21. Murrell GA, Jang D, Williams RJ 1995 Nitric oxide activates metalloprotease enzymes in articular cartilage. Biochem Biophys Res Commun 206:15-21

22. Ekekezie II, Thibeault DW, Rezaiekhaligh MH, Mabry SM, Norberg M, Reddy GK, Youssef J, Truog WE 2000 High dose inhaled nitric oxide and hyperoxia increases lung collagen accumulation in piglets. Biol Neonate 78:198-206

23. Hsu SM, Raine L, Fanger H 1981 Use of avidin-biotin peroxidase complex (ABC) in immunoperoxidase techniques: a comparison between $\mathrm{ABC}$ and unlabeled antibody (PAP) procedures. J Histochem Cytochem 29:577-580

24. Maniscalco WM, Watkins RH, D'Angio CT, Ryan RM 1997 Hyperoxic injury decreased alveolar epithelial cell expression of vascular endothelial growth (VEGF) in neonatal rabbit lung. Am J Respir Cell Mol Biol 16:557-567

25. Watkins RH, D'Angio CT, Ryan RM, Patel A, Maniscalco WM 1999 Differential expression of VEGF mRNA splice variants in newborn and adult hyperoxic lung injury. Am J Physiol 276:L858-L867

26. Houck KA, Leung DW, Rowland AM, Winer J, Ferrara N 1992 Dual regulation of vascular endothelial growth factor bioavailability by genetic and proteolytic mechanisms. J Biol Chem 267:26031-26037

27. Erichsen JT, Jarvis-Evans J, Khaliq A, Boulton M 2001 Oxygen modulates the release of urokinase and plasminogen activator inhibitor-1 by retinal pigment epithelial cells. Int J Biochem Cell Biol 33:237-247

28. Radomski A, Sawicki G, Olson DM, Radomski MW 1998 The role of nitric oxide and metalloproteinases in the pathogenesis of hyperoxia-induced lung injury in newborn rats. Br J Pharmacol 125:1455-1462

29. Devaskar UP, Taylor W, Govindrajan R, Malicdem M, Heyman S, deMello DE 1994 Hyperoxia induces interstitial (type I) and increases type IV collagenase mRNA expression and increased type I and IV collagenolytic activity in newborn rat lung. Biol Neonate 66(2-3):76-85

30. Neufeld G, Cohen T, Gitay-Goren H, Poltorak Z, Tessler S, Sharon R, Gengrinovitch S, Levi BZ 1996 Similarities and differences between the vascular endothelial growth factor (VEGF) splice variants. Cancer Metastasis Rev 15:153-158

31. Poltorak Z, Cohen T, Neufeld G 2000 The VEGF splice variants: properties, receptors and usage for the treatment of ischemic diseases. Herz 25:126-129 